Tropical Journal of Pharmaceutical Research March 2019; 18 (3): 571-577

ISSN: $1596-5996$ (print); 1596-9827 (electronic)

(C) Pharmacotherapy Group, Faculty of Pharmacy, University of Benin, Benin City, 300001 Nigeria.

\title{
Methanol extract of Aruncus dioicus exerts antidiabetic effect via PCSK9/LDLR pathway
}

\author{
Li Gong ${ }^{1 *}$, Qing Yang ${ }^{2}$, Yinluan Huang ${ }^{1}$, Shaoyan Xie ${ }^{1}$, Chao Zeng ${ }^{1}$, Yuzhou \\ Liu $^{1}$ \\ ${ }^{1}$ Department of Diabetes, Shenzhen Baoan Traditional Chinese Medicine Hospital Group, The Affiliated Hospital of Guangzhou \\ University of Chinese Medicine, Shenzhen, $518133,{ }^{2}$ School of Chinese Medicine, Hong Kong Baptist University, Hong Kong \\ 999077, China
}

*For correspondence: Email: GracielaLgega@yahoo.com; Tel: 0086-0755-29629333

Sent for review: 18 September 2018

Revised accepted: 16 February 2019

\begin{abstract}
Purpose: To investigate the antidiabetic effect of methanol extract of Aruncus dioicus, and the underlying mechanism(s).

Methods: Twenty-four adult female albino mice were randomly assigned to four groups of six mice each: normal control group, diabetic control group and two treatment groups. With the exception of normal control group, the diabetic control and treatment groups consisted of leptin receptor-deficient $(d b / d b)$ type 2 diabetic mice. The diabetic control group was not treated, while the treatment groups received 200 or $400 \mathrm{mg} / \mathrm{kg}$ extract/day orally for 4 weeks. The effect of the extract on fasting blood glucose (FBG), proprotein convertase subtilisin/kexin type 9 (PCSK9), glycogen and lipid profiles were determined. The expressions of PCSK9, low-density lipoprotein receptor (LDL-R) and glucokinase (GCK) were determined in liver tissues using western blotting and real-time quantitative polymerase chain reaction ( $q R T-P C R)$.

Results: Fasting blood glucose (FBG) was significantly and dose-dependently reduced in the treatment groups, relative to diabetic control group at different time-points $(p<0.05)$. Total cholesterol $(T C)$, triacylglycerol (TG), low-density lipoprotein cholesterol (LDL-C) and high-density lipoprotein cholesterol $(H D L-C)$ were significantly higher in the diabetic control group than in normal control group $(p<0.05)$. However, treatment with methanol extract of $A$. dioicus significantly and dose-dependently reversed the changes in the levels of these parameters $(p<0.05)$. The expressions of LDLR and GCK were significantly down-regulated in diabetic control group, when compared with normal control group, but their expressions were significantly dose-dependently upregulated in the treatment groups $(p<0.05)$. Treatment with the extract significantly and dose-dependently down-regulated PCSK9 expression ( $p<$ $0.05)$. Liver injury characterized by large distended lipid droplets and fat accumulation was seen in diabetic mice, but treatment with methanol extract of $A$. dioicus significantly reversed the histopathological changes induced by DM.

Conclusion: These results indicate that the antidiabetic effect of methanol extract of $A$. dioicus is exerted via a mechanism involving PCSK9/LDLR pathway.
\end{abstract}

Keywords: Aruncus dioicus, Diabetes mellitus, Proprotein convertase subtilisin/kexin type 9, Fasting blood glucose, Low-density lipoprotein receptor

This is an Open Access article that uses a funding model which does not charge readers or their institutions for access and distributed under the terms of the Creative Commons Attribution License (http://creativecommons.org/licenses/by/4.0) and the Budapest Open Access Initiative (http://www.budapestopenaccessinitiative.org/read), which permit unrestricted use, distribution, and reproduction in any medium, provided the original work is properly credited.

Tropical Journal of Pharmaceutical Research is indexed by Science Citation Index (SciSearch), Scopus, International Pharmaceutical Abstract, Chemical Abstracts, Embase, Index Copernicus, EBSCO, African Index Medicus, JournalSeek, Journal Citation Reports/Science Edition, Directory of Open Access Journals (DOAJ), African Journal Online, Bioline International, Open-J-Gate and Pharmacy Abstracts 


\section{INTRODUCTION}

Diabetes mellitus (DM) is a group of heterogeneous disorders characterized by high blood glucose, and it can be type 1 or type 2 . Disorders in the metabolism of glucose and lipids are the hallmarks of DM, and these result in micro- and macrovascular complications [1, 2]. The treatment of DM involves the use of agents that possess hypolipidemic and hypoglycemic properties. Proprotein convertase subtilisin/kexin type 9 (PCSK9) has been implicated as a drug target in the treatment of DM [3]. Studies have shown that LDLR regulates cholesterol level by controlling its uptake, and its degradation depends on PCSK9 [4]. Clinical and preclinical studies have also shown that there is a link between glucose metabolism and PCSK9 [5]. Insulin resistance in DM is reduced by controlling plasma lipid levels via the upregulation of PCSK9 expression [6].

The use of alternative medicine in the management of diseases has continued to receive increasing attention over the last decades.

Aruncus dioicus, known as goat's beard, buck'sbeard or bride's feathers, is a flowering herbaceous perennial plant in the Rosaceae family. It grows in different parts of the world including America, Asia and Europe [7]. This plant is used in Traditional Chinese Medicine (TCM) to treat tonsillitis, scars, poisoning and skin disorders [8]. Aruncus dioicus is a reservoir of bioactive compounds such as caffeic acid, 1O-caffeoyl- $\beta$-D-glucopyranose, aruncide $A$, prunasin and sambunigrin [9].

The whole plant extract of $A$. dioicus exerts antiapoptotic effect on neuronal and renal injuries $[10,11]$ and has also been shown to possess potent antioxidant and anti-aging properties. The aim of this study was to investigate the antidiabetic effect of methanol extract of A. dioicus, and the underlying mechanism(s) of action.

\section{EXPERIMENTAL}

\section{Materials}

Female albino leptin receptor-deficient $(d b / d b)$ type 2 diabetic mice were purchased from Experimental Animal Centre of the Academy of Military Medical Sciences, China. Enzyme-linked immunosorbent assay (ELISA) kits were obtained from Santa Cruz Biotechnology Inc. (USA), while automated biochemical analyzer was a product of Olympus AU1000 (Japan).
RNAiso plus and PrimeScript ${ }^{\mathrm{TM}} \mathrm{RT}$ reagent kits were products of Takara Biotechnology Inc. (Japan), while RT2 SYBR Green Master was purchased from Thermo Fisher Scientific Inc. (USA). Protein extraction and bicinchoninic acid (BCA) assay kits were products of Sangon Biotech Co., Ltd.

\section{Experimental mice}

The female albino mice used in this study were aged 5 to 6 weeks. They were housed in plastic cages under standard conditions of animal care, and had free access to standard feed and water. The mice were exposed to 12-h light/12-h dark cycle and maintained at $25{ }^{\circ} \mathrm{C}$ and $48 \%$ humidity. The study protocol was approved by the Institutional Animal Care and Use Committee of the Affiliated Hospital of Guangzhou University of Chinese Medicine, China (No. IACUC/AHGUCM/2017/02), and the study procedures were carried out according to the guidelines of Association for the Assessment and Accreditation of Laboratory Animal Care International (AAALAC) [12].

\section{Preparation of extract}

Whole plant of Aruncus dioicus was purchased from a botanical garden and identified at the Botanical Research Center, Shanghai, China. The whole plant was dried under shade and pulverized using a mechanical blender. A portion of the powder $(500 \mathrm{~g})$ was suspended in $1000 \mathrm{ml}$ of methanol and stirred intermittently at intervals of $2 \mathrm{~h}$, and left overnight. After $72 \mathrm{~h}$, the mixture was filtered, and the filtrate was concentrated using a vacuum rotatory evaporator. It was then freeze-dried by lyophilization.

\section{Animal studies}

Twenty-four adult female albino mice were randomly assigned to four groups of six mice each: normal control group, diabetic control group and two treatment groups. With the exception of normal control group, the diabetic control and treatment groups consisted of leptin receptor- deficient $(d b / d b)$ type 2 diabetic mice. The diabetic control group was not treated, while the treatment groups received 200 or $400 \mathrm{mg} / \mathrm{kg}$ extract/day orally for 4 weeks. The FBG was determined on weekly basis using blood collected from the retro-orbital plexus of mice.

\section{Collection of blood and tissue samples}

After 4 weeks of treatment, the mice were sacrificed under isoflurane anaesthesia and blood samples were collected through cardiac 
puncture. The blood was centrifuged at $3000 \mathrm{rpm}$ for $10 \mathrm{~min}$ at room temperature to obtain serum which was used for biochemical analysis. Their liver tissues were also excised for analysis and stored in liquid nitrogen at $-80^{\circ} \mathrm{C}$.

\section{Determination of PCSK9 level and lipid profile}

The serum levels of TC, TG, LDL-C and HDL-C were determined using automated biochemical analyzer, while serum level of PCSK9 was determined using ELISA kit.

\section{Evaluation of tissue TG, TC and glycogen}

The liver was homogenized with physiological saline and the resultant homogenate was partitioned into three layers with a mixture of chloroform and methanol $(2: 1, \mathrm{v} / \mathrm{v})$. The lipid layer was used for the determination of tissue TG and TC. Glycogen level in the diluted homogenate was determined after hydrolyzing it with a base for $20 \mathrm{~min}$.

\section{Western blotting}

Liver homogenate was prepared using radioimmunoprecipitation assay (RIPA) buffer. The resultant tissue homogenate was washed twice with phosphate-buffered saline (PBS) and centrifuged at $13,000 \mathrm{~g}$ for $25 \mathrm{~min}$ at $4{ }^{\circ} \mathrm{C}$. The protein concentration of the supernatant was determined using BCA assay kit. A portion of total tissue protein $(20-30 \mu \mathrm{g})$ from each sample was separated on $8 \%$ sodium dodecyl sulphate (SDS)-polyacrylamide gel electrophoresis and transferred to a fixed polyvinylidene fluoride membrane at $110 \mathrm{~V}$ and $90{ }^{\circ} \mathrm{C}$ for $120 \mathrm{~min}$. Subsequently, non-fat milk (3\%) in Tris-buffered saline containing $0.2 \%$ Tween-20 (TBS-T) was added with gentle shaking and incubated at 37 ${ }^{\circ} \mathrm{C}$ to block non-specific binding of the blot. Incubation of the blots was performed overnight at $4{ }^{\circ} \mathrm{C}$ with primary antibodies for PCSK9, LDLR, GCK, and tubulin at a dilution of 1 to 500 . Then, the membrane was washed thrice with TBS-T and further incubated with horseradish peroxidase-conjugated goat anti-rabbit $\lg G$ secondary antibody for $1 \mathrm{~h}$ at room temperature. The blot was developed using an X-ray film. Grayscale analysis of the bands was performed using ImageJ analysis software (4.6.2). Respective protein expression levels were normalized to that of tubulin which was used as a standard reference.

\section{Quantitative polymerase chain reaction (qRT- PCR)}

Total RNAs were isolated from portions of liver homogenate using RNAiso plus and assayed spectrophotometrically. The RNAs were reversetranscribed to cDNAs, using random primers at $45^{\circ} \mathrm{C}$ for $2 \mathrm{~h}$. PrimeScript ${ }^{\mathrm{TM}} \mathrm{RT}$ reagent kit was used to synthesize the cDNA from total RNA. The PCR amplification of the reverse-transcribed reaction mixture was carried out using $20 \mu \mathrm{l}$ reaction mixture with equal volume of RT2 SYBR Green Master. The PCR conditions were: predenaturation at $95{ }^{\circ} \mathrm{C}$ for $30 \mathrm{~s}$, denaturation at 95 ${ }^{\circ} \mathrm{C}$ for $3 \mathrm{~s}$, annealing at $60{ }^{\circ} \mathrm{C}$ for $34 \mathrm{~s}$, and 50 cycles. The procedure was performed in triplicate. Relative expression was quantified using Stratagene Mx3000P software, with $\beta$-actin gene as internal reference. The primers sequences used for qRT-PCR are shown in Table 1.

\section{Histopathological examination}

Histological examination of the liver was performed using hematoxylin and eosin (H\&E) staining, and histopathological changes were identified using trina ocular microscope.

\section{Statistical analysis}

Data are expressed as mean \pm SEM, and the statistical analysis was performed using SPSS (version 20.0). Groups were compared using Dunnett's multiple test range. Values of $p<0.05$ were considered statistically significant.

\section{RESULTS}

\section{Effect of extract on FBG}

The level of FBG was significantly and dosedependently reduced in the treatment groups, relative to diabetic control group at the different time points $(p<0.05$; Figure 1$)$.

Table 1: Primer sequences used for qRT-PCR

\begin{tabular}{|c|c|c|}
\hline \multirow[t]{2}{*}{ Gene } & \multicolumn{2}{|c|}{ Primer Sequences } \\
\hline & Reverse & Forward \\
\hline LDLR & ACCTGCCGACCTGATGAATTC & GCAGTCATGTTCACGGTCACA \\
\hline PCSK9 & TTGCAGCAGCTGGGAACTT & CCGACTGTGATGACCTCTGGA \\
\hline
\end{tabular}




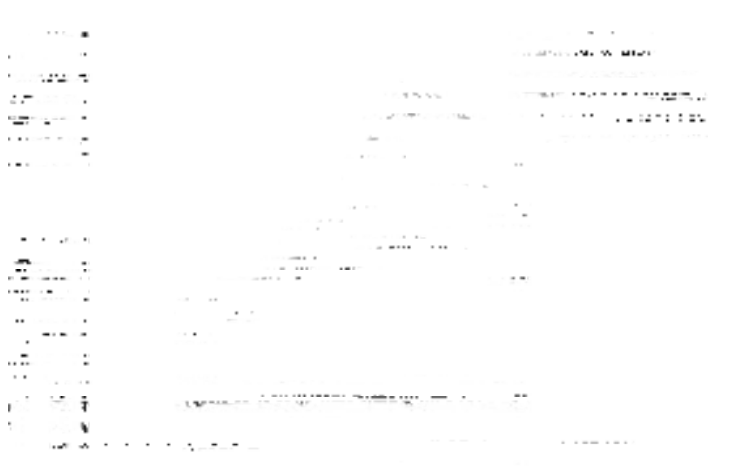

Figure 1: Effect of methanol extract of $A$. dioicus on FBG. ${ }_{*}^{\# \#}<0.05$, when compared to normal control group; ${ }^{\star} p<0.05$, when compared to diabetic control group

\section{Effect of methanol extract of A. dioicus on lipid profiles}

The levels of TC, TG, LDL-C and HDL-C were significantly higher in the diabetic control group than in normal control group $(p<0.05)$. However, treatment with methanol extract of $A$. dioicus significantly and dose-dependently reversed changes in the levels of these parameters $(p<$ 0.05; Table 2).

\section{Effect of methanol extract of A. dioicus on levels of glycogen, PCSK9, TG and TC}

The level of liver glycogen was significantly reduced in diabetic control group, relative to the normal control group, but was significantly dosedependently increased after treatment with the extract $(p<0.05)$. There were no significant differences in the serum levels of PCSK9 among the groups $(p>0.05)$. Liver TG and TC were significantly higher in diabetic control group than in normal control group, but were significantly and dose-dependently decreased in the treatment groups $(p<0.05)$. These results are shown in Figure 2.

Table 2: Effect of methanol extract of $A$. dioicus on lipid profiles

\begin{tabular}{|c|c|c|c|c|}
\hline Group & HDL-C (mmol/L) & LDL-C (mmol/L) & $\mathrm{TG}(\mathrm{mmol} / \mathrm{L})$ & $\begin{array}{c}\mathrm{TC} \\
(\mathrm{mmol} / \mathrm{L})\end{array}$ \\
\hline Normal control & $1.13 \pm 0.19$ & $0.42 \pm 0.01$ & $1.59 \pm 0.24$ & $1.96 \pm 0.14$ \\
\hline Diabetic control & $2.18 \pm 0.23^{\mathrm{a}}$ & $0.78 \pm 0.03^{\mathrm{a}}$ & $2.83 \pm 0.31^{\mathrm{a}}$ & $4.39 \pm 0.37^{\mathrm{a}}$ \\
\hline $200 \mathrm{mg} / \mathrm{kg}$ bwt extract & $2.24 \pm 0.16^{\mathrm{ab}}$ & $0.64 \pm 0.02^{\mathrm{ab}}$ & $2.16 \pm 0.17^{\mathrm{ab}}$ & $3.32 \pm 0.21^{\mathrm{ab}}$ \\
\hline $400 \mathrm{mg} / \mathrm{kg}$ bwt extract & $2.57 \pm 0.21^{\mathrm{abc}}$ & $0.51 \pm 0.03^{\mathrm{abc}}$ & $1.73 \pm 0.21^{\mathrm{abc}}$ & $2.73 \pm 0.19^{\mathrm{abc}}$ \\
\hline
\end{tabular}
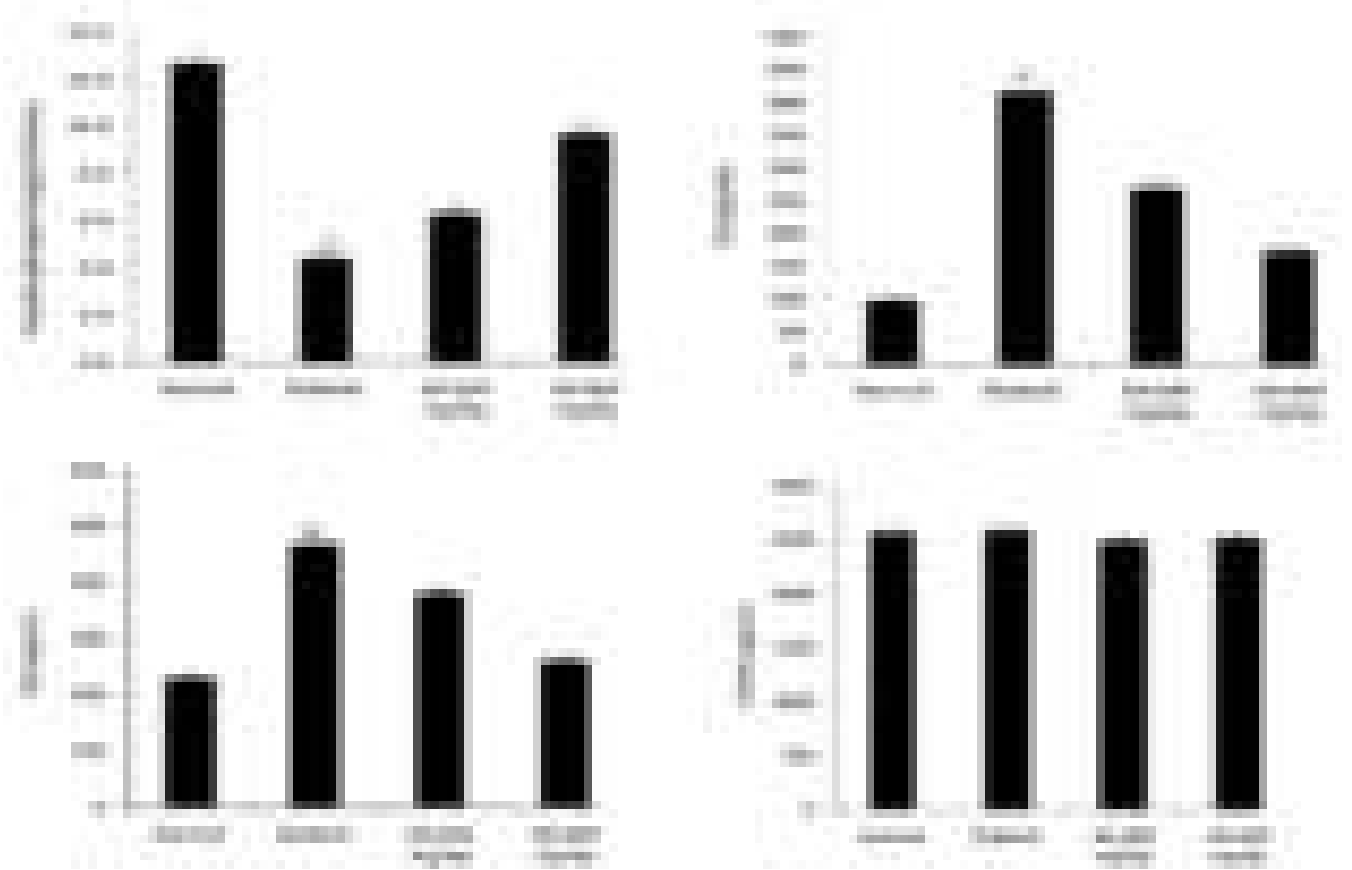

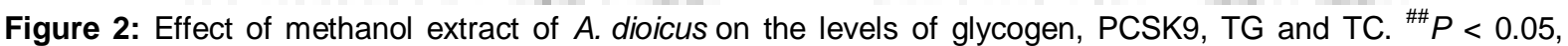
when compared to normal control group; ${ }^{* *} p<0.05$, when compared to diabetic control group 


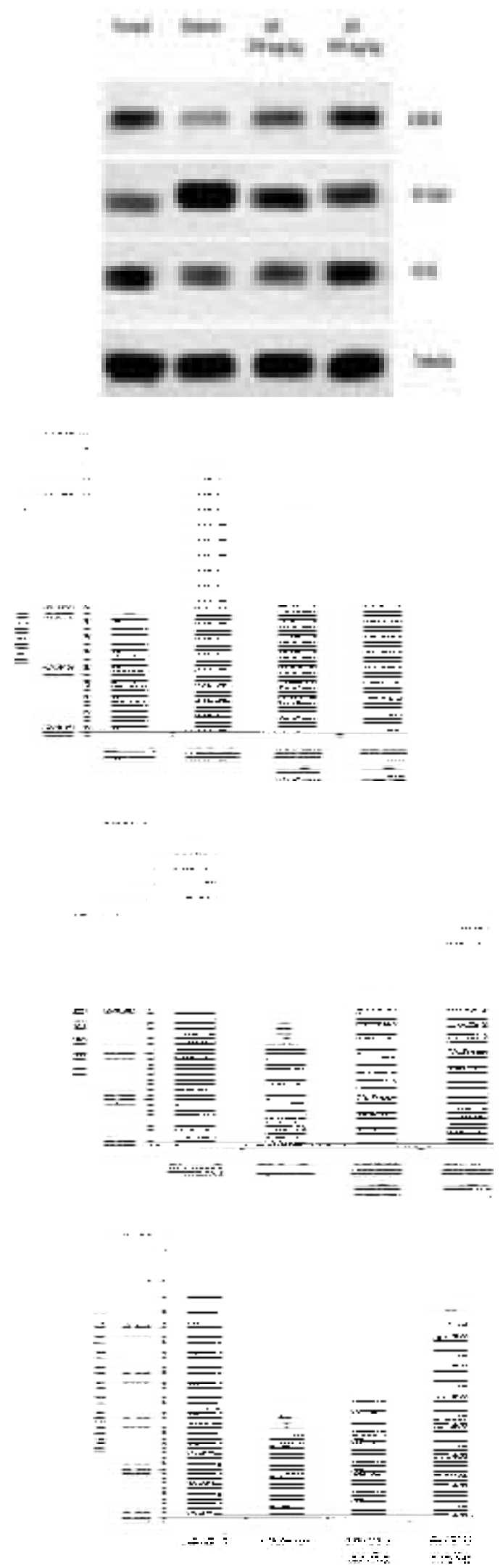

Figure 3: Effect of methanol extract of $A$. dioicus on PCSK9, LDLR and GCK expressions in the liver. ${ }^{\# \#} P<$ 0.05 , when compared to normal control group; ${ }^{*} p<$ 0.05 , when compared to diabetic control group; ${ }^{\star *} p<$ 0.05 , when compared to $200 \mathrm{mg} / \mathrm{kg}$ group

\section{Expressions of PCSK9, LDLR and GCK}

The expressions of LDLR and GCK were significantly down-regulated in diabetic control group, when compared with normal control group, but their expressions were significantly upregulated dose-dependently in the treatment groups $(p<0.05)$. The level of expression of PCSK9 was significantly higher in diabetic control group than in normal control group $(p<$ 0.05). However, treatment with extract significantly down-regulated PCSK9 expression dose-dependently ( $p<0.05$; Figure 3$)$.

\section{Effect of methanol extract of A. dioicus on expressions of PCSK9 and LDLR mRNAs}

qRT-PCR results showed that the expression of PCSK9 mRNA was upregulated by a factor of 1.86, while the expression of LDLR mRNA was down-regulated by a factor of 0.62 in the liver of diabetic control mice, when compared with normal control group $(p<0.05)$. However, treatment with methanol extract of $A$. dioicus significantly reversed the changes in the level of expressions of PCSK9 and LDLR mRNAs induced by DM $(p<0.05$; Figure 4$)$.
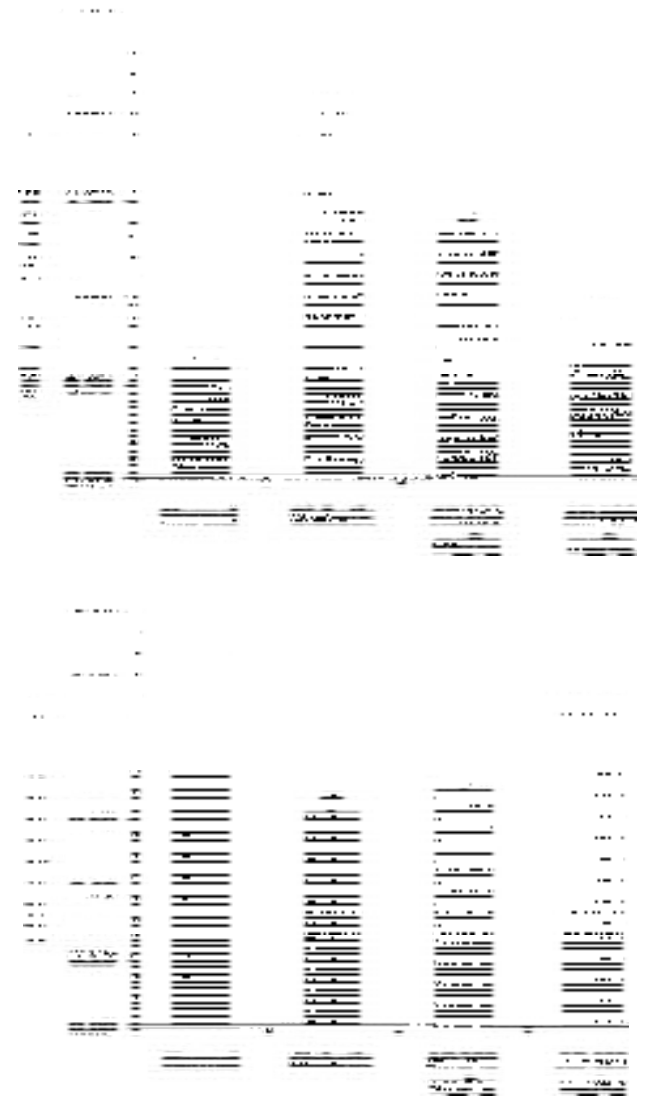

Figure 4: Effect of methanol extract of $A$. dioicus on PCSK9 and LDLR mRNA expression. ${ }^{\# \#} P<0.05$ when compared to normal control group; ${ }^{* *} p<0.05$ when compared to diabetic control group 


\section{Histopathological features}

Liver injury characterized by large distended lipid droplets and fat accumulation was observed in diabetic mice. However, treatment with methanol extract of $A$. dioicus significantly reversed the histopathological changes induced by DM (Figure 5).

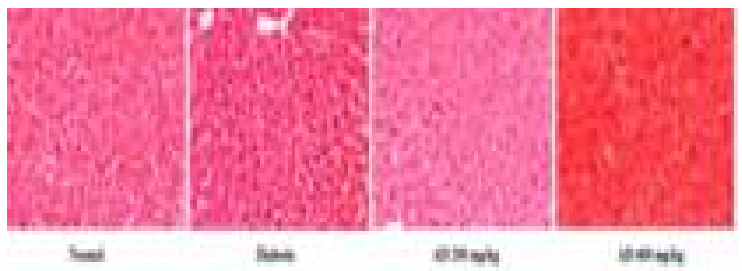

Figure 5: Effect of methanol extract of $A$. dioicus on liver histology. (H\&E staining, $x$ 400)

\section{DISCUSSION}

Type 1 DM (TIDM) is due to insulin deficiency, while type 2 DM (T2DM) is caused by insulin resistance [1]. Leptin and leptin receptor-deficient $(d b / d b)$ rodent model is a well-established model of T2DM characterized by insulin resistance, dyslipidemia, hyperglycemia and obesity [13]. It has been reported that the development of diabetic complications is slowed down or prevented by controlling plasma levels of lipids and glucose [2].The importance of alternative medicine in the management of DM cannot be overemphasized. The present study investigated the antidiabetic effect of methanol extract of A. dioicus, and the underlying mechanism(s). The results of this study showed that treatment with methanol extract of $A$. dioicus significantly reduced FBG and ameliorated altered lipid profiles induced by DM. These results suggest that the extract may normalize altered glucose level and lipid profiles in diabetic mice. Histopathological examination also showed that treatment with the extract significantly reversed histological changes induced by DM.

Low-density lipoprotein receptor (LDLR) plays a key role in the maintenance of plasma level of lipids [14]. It is likely that blood lipid homeostasis is achieved by increased cholesterol clearance. It has been reported that PCSK9 is expressed in many cells and tissues, where it binds to LDLR present on membranes of such cells [15]. Insulin resistance is reduced by controlling plasma lipid level via the upregulation of PCSK9 expression, and PCSK9 in turn reduces the expression of LDLR by promoting its degradation [6]. Glucokinase (GCK) catalyzes the phosphorylation of glucose to yield glucose 6phosphate in liver cells, and its expression is usually reduced in DM [16]. The results of
Western blotting and qRT-PCR showed that treatment with methanol extract of $A$. dioicus significantly upregulated the expression of LDLR and significantly down-regulated the expression of PCSK9 in diabetic mice. The expression of GCK was also significantly upregulated in extract-treated groups, when compared with the diabetic control group.

\section{CONCLUSION}

These results indicate that the antidiabetic effect of methanol extract of $A$. dioicus is exerted via a mechanism involving PCSK9/LDLR pathway. Thus, the extract has potentials for further development as an anti-diabetic therapy for humans.

\section{DECLARATIONS}

\section{Acknowledgement}

The authors of the manuscript are thankful to Shenzhen Baoan Traditional Chinese Medicine Hospital Group, The Affiliated Hospital of Guangzhou University of Chinese Medicine, China for providing the facilities for this study.

\section{Conflict of interest}

No conflict of interest is associated with this work.

\section{Contribution of authors}

We declare that this work was done by the authors named in this article and all liabilities pertaining to claims relating to the content of this article will be borne by the authors. This work was designed by $\mathrm{Li}$ Gong. Qing Yang and Yinluan Huang performed all the experiments. Shaoyan Xie and Chao Zeng gave assistance to collect materials. Yuzhou Liu gave good suggestions for designing this work.

\section{REFERENCES}

1. Cade WT. Diabetes-Related Microvascular and Macrovascular Diseases in the Physical Therapy Setting. Physical Therapy. 2008; 88: 1322-1335.

2. Asif $M$. The prevention and control the type-2 diabetes by changing lifestyle and dietary pattern. J Educ Health Promot. 2014; 3: 1.

3. Schmidt AF, Swerdlow DI, Holmes MV, Patel RS, Fairhurst-Hunter Z, Lyall DM, Hartwig FP, Horta BL, Hyppönen E, Power C, et al. PCSK9 genetic variants and risk of type 2 diabetes: a mendelian randomisation study. Lancet Diabetes Endocrinol. 2017; 5: 97-105. 
4. Lagace TA. PCSK9 and LDLR degradation: regulatory mechanisms in circulation and in cells. Curr Opin Lipidol 2014; 25: 387-393.

5. Glerup S, Schulz R, Laufs U, Schlüter K-D. Physiological and therapeutic regulation of PCSK9 activity in cardiovascular disease. Basic Res Cardiol. 2017; 112 32.

6. Schulz R, Schlüter K-D. PCSK9 targets important for lipid metabolism. Clin Res Cardiol Suppl. 2017; 12: 2-11.

7. Dowidar AE, Loutfy MHA, Kamel EA, Ahamed AHM and Hafez HHL, Studies on the Rosaceael- Seed and/or Achene Macro and Micromorphology. Pak J Biol Sci. 2003; 6: 1778-1791.

8. Granica S, Fusani P, Stanisławska I, Piwowarski JP, Melck D, Motta A, Zidorn C., Monoterpenoids from the traditional North Italian vegetable Aruncus dioicus (Walter) Fernald var. vulgaris (Maxim.) H.Hara (Rosaceae). Food Chem. 2017; 221: 1851-1859.

9. Vo $Q H$, Nguyen $P H$, Zhao $B T$, Thi $Y N$, Nguyen $D H$, Kim WI, Seo UM, Min BS, Woo MH. Bioactive Constituents from the $n$-Butanolic Fraction of Aruncus dioicus var. kamtschaticus. Nat Prod Res. 2014; 4: 274-280.

10. Baek HS, Lim SH, Ahn KS, Lee J. Methanol Extract of Goat's-beard (Aruncus dioicus) Reduces Renal Injury by Inhibiting Apoptosis in a Rat Model of IschemiaReperfusion. Prev Nutr Food Sci. 2012; 17: 101-108.

11. Park SB, Lee U, Kang JY, Kim JM, Park SK, Park SH, Choi SG, Heo HJ, Protective effects of Aruncus dioicus var. kamtschaticus extract against hyperglycemicinduced neurotoxicity. Korean J. Food Sci. Technol 2017; 49: 668-675

12. Guide for the Care and Use of Laboratory Animals: Eighth Edition Committee for the Update of the Guide for the Care and Use of Laboratory Animals; National Research Council. 2010; ISBN: 0-309-15401-4.

13. Kobayashi K, Forte TM, Taniguchi S, Ishida BY, Oka K, Chan L., The $d b / d b$ mouse, a model for diabetic dyslipidemia: molecular characterization and effects of Western diet feeding. Metabolism. 2000; 49: 22-31.

14. Zhang Y, Ma KL, Ruan XZ, Liu BC. Dysregulation of the Low-Density Lipoprotein Receptor Pathway is Involved in Lipid Disorder-Mediated Organ Injury. Int J Biol Sci. 2016; 12: 569-579.

15. Roubtsova A, Chamberland A, Marcinkiewicz J, Essalmani R, Fazel A, Bergeron JJ, Seidah NG, Prat A. PCSK9 deficiency unmasks a sex- and tissue-specific subcellular distribution of the $L D L$ and VLDL receptors in mice. J Lipid Res. 2015; 56: 2133-2142.

16. Da Dalt L, Ruscica M, Bonacina F, Balzarotti G, Dhyani A, Di Cairano E, Baragetti A, Arnaboldi L, De Metrio S, Pellegatta F, Grigore L, Botta M, Macchi C, Uboldi $P$, Perego C, Catapano AL, Norata GD, PCSK9 deficiency reduces insulin secretion and promotes glucose intolerance: the role of the low-density lipoprotein receptor. Eur Heart J. 2018. 